\section{Development of an Embryo Rescue Protocol for Butterfly Weed}

\author{
Mary Lewis ${ }^{1}$, Matthew Chappell ${ }^{1}$, Donglin Zhang ${ }^{1}$, \\ and Rebekah Maynard ${ }^{1}$
}

Additional InDeX words. Asclepiadaceae, Asclepias tuberosa, autotrophic embryo, germination percent, native plant

SummaRY. We documented a successful embryo rescue (ER) protocol for butterfly weed (Asclepias tuberosa), a member of the milkweed family (Asclepiadaceae). Milkweed (Asclepias sp.) includes more than 100 species native to the United States, is an important pollinator plant, and has many commercially desirable traits. However, there is little commercial production outside of native plant nurseries because milkweed species are typically seed-grown and suffer from low seed set during pollination, late-term abortion of seed pods, and nonuniform germination. This project determined the optimal growing media (study one) and embryo maturity (study two) to recover mature seedlings from excised embryos and compared the results to those of traditional methods of seed germination (in soilless substrate). Study one investigated three different media: Murashige and Skoog (MS) medium at full strength and half strength and woody plant medium. MS medium at half strength was optimal for butterfly weed germination and maturation, with greater root and shoot lengths at the time of harvest. In study two, the effects of MS medium at half strength on embryo maturation 90, 60, and 30 days after pollination (DAP) were investigated. The optimal time to harvest embryos was 60 DAP; embryos at $30 \mathrm{DAP}$ were capable of germination but not maturation. A mean germination rate of $97.4 \%$ was observed when using embryo rescue, but it was 72.3\% with mature seed germinated in soilless substrate typical of commercial production. A similar increase in germination rates was observed for all embryo maturities when compared with seed germinated using soilless substrate. The protocol developed for this study should help to standardize production, reduce propagation time, and improve the commercial acceptance and profitability of milkweed.

$\mathrm{E}$ mbryo rescue (ER), or the excision and culturing of immature zygotic embryos from developing seeds, is conducted under aseptic conditions to obtain viable and pathogen-free plantlets (Bhojwani and Razdan, 1986; Morel, 1960). The technique was first documented by Charles Bonnet in the late 18th century, and it has been commercially

Received for publication 25 June 2019. Accepted for publication 11 Sept. 2019.

Published online 25 November 2019.

${ }^{1}$ Department of Horticulture, University of Georgia, 1111 Miller Plant Science Building, Athens, GA 30602

We appreciate the support of Dr. Ockert Greyvenstein (Ball Horticulture), Dr. Paul Thomas (University of Georgia, Department of Horticulture), Foothills Compost Inc., Pan American Seed, Harrell's Fertilizers LLC, and the UGA Research Foundation for support of this project. Additionally, we appreciate the support of Dr. Carol Robacker, Dr. Julie Campbell, and Dr. John Ruter for providing internal reviews.

M.C. is the corresponding author. E-mail: hortprod@ uga.edu.

This is an open access article distributed under the CC BY-NC-ND license (https://creativecommons.org/ licenses/by-nc-nd/4.0/).

https://doi.org/10.21273/HORTTECH04440-19 practiced for more than half a century (Bridgen, 1994). Further research by Hannig (1904) refined the technique and laid the groundwork that would allow future scientists to bypass physical and/or late-onset chemical seed dormancy, shorten breeding cycles, examine seed/embryo viability, and develop hybrids from previously incompatible crosses (Bridgen, 1994). In plant breeding programs, ER is particularly critical because it can circumvent seed abortion of wide crosses, resulting in the retention of novel genotypes (Conger, 1981; Dunwell, 1986). Embryo rescue has also been widely used to efficiently propagate threatened and/or endangered species because it has been noted to improve germination rates (Lakshmi et al., 2010; Stephenson and Fahey, 2004).

Butterfly weed (Asclepias tuberosa) is one of 106 species that are indigenous to North America (Stevens, 1945; Woodson, 1954). Although milkweed (Asclepias) species have many ornamental and ecologically important traits, there is little commercial production outside of niche native plant growers. Limited commercial production is thought to result from limited seed set because milkweed species frequently display late-term seed and pod abortion, possibly due to complex reproductive structures (Broyles, 2002; Kephart, 1981; Shannon and Wyatt, 1986). The predominant theory regarding the failure of intraspecific and interspecific seed development in milkweed species is that late-term embryo abortion is attributed to postfertilization rejection, whereby fertilization of the endosperm is successful but the egg (precursor to the zygote) remains unfertilized. Gametophytic and sporophytic self-incompatibility systems typically experience abortion between a few hours to a few days after pollination; however, in milkweed species, late-term abortion can occur several weeks to 2 months after fertilization (Lipow and Wyatt, 2000; Seavey and Bawa, 1986; Sparrow and Pearson, 1948; Whiting, 1943). Embryo abortion is difficult to overcome; however, by prematurely harvesting seeds, removing the embryo, and aseptically culturing the embryo on nutrient medium, pod abortion and developmental failure could be circumvented.

There are no published ER protocols available for milkweed species. Several studies document embryogenesis protocols for milkweed species from cell cultures, leaf tissue, or nodal explants (Groet and Kidd, 1981; Kim et al., 2004; Pramanik and Datta, 1986; Sahai et al., 2010). Embryogenesis, compared with ER, takes longer because embryonic tissue

\begin{tabular}{llll}
\hline $\begin{array}{l}\text { Units } \\
\text { To convert U.S. to SI, } \\
\text { multiply by }\end{array}$ & U.S. unit & SI unit & $\begin{array}{l}\text { To convert SI to U.S., } \\
\text { multiply by }\end{array}$ \\
\hline 29.5735 & $\mathrm{fl} \mathrm{oz}$ & $\mathrm{mL}$ & 0.0338 \\
3.7854 & gal & $\mathrm{L}$ & 0.2642 \\
2.54 & inch $(\mathrm{es})$ & $\mathrm{cm}$ & 0.3937 \\
25.4 & inch $(\mathrm{es})$ & $\mathrm{mm}$ & 0.0394 \\
28.3495 & $\mathrm{Oz}$ & $\mathrm{g}$ & 0.0353 \\
$\left({ }^{\circ} \mathrm{F}-32\right) \div 1.8$ & ${ }^{\circ} \mathrm{F}$ & ${ }^{\circ} \mathrm{C}$ & $\left({ }^{\circ} \mathrm{C} \times 1.8\right)+32$
\end{tabular}


must first be dedifferentiated, multiplied via callus formation, and then redifferentiated with the aid of plant growth regulators (PGRs) (Kim et al., 2004). Although large nutritional differences in ER protocols compared to those of embryogenesis protocols exist, a study of embryogenesis of indian ipecac (Tylophora indicia) found that this species, also in the milkweed family (Asclepiadaceae), preferred a relatively lower nutrient content compared with other taxa (Sahai et al., 2010). A half-strength MS medium increased explant regeneration of indian ipecac by more than $20 \%$ when applied at embryo maturation compared with other commonly used media (Sahai et al., 2010).

ER may be a commercially viable mechanism to overcome seed pod abortion if the embryo is excised from the seed at a point when it has reached the autotrophic (self-sufficient) stage but before seed pod abortion. However, an ER protocol for butterfly weed has not been documented; therefore, medium type, days of stratification, seed/explant cleaning methods, embryo culture environmental conditions, and the effect of embryo maturity on success are unknown. The primary objectives of this project were to 1 ) determine if it is possible to rescue embryos in the autotrophic stage through the development of an ER methodology; 2) assess the optimum embryo maturity to harvest seed and excise embryos for maximum growth of germinated embryos; and 3) determine if ER methods offer an improvement over seed germination rates using traditional seed germination in soilless substrates determine. Based on previous research of another milkweed species (indian ipecac), we hypothesized that media with less nutrition would be superior for successful germination of autotrophic embryos. We also predicted that germination rates of rescued embryos would exceed those observed with traditional commercial settings, and that embryos harvested in the heterotrophic phase of development would fail to produce viable plantlets.

\section{Materials and methods}

Parent and Seed PRODUCtion. Stock plants of butterfly weed were produced from three wild-collected seed pods from a single plant (Oglethorpe County, GA) in Aug. 2017, dry-stored until Jan. 2018, and cool moist-stratified at $2{ }^{\circ} \mathrm{C}$ for 6 weeks. Seeds were germinated in Mar. 2018 at the College Station Greenhouse Complex (lat. $33.9480^{\circ} \mathrm{N}$, long. $83.3773^{\circ} \mathrm{W}$; U.S. Department of Agriculture zone $8 \mathrm{a}$ ) at the University of Georgia Athens campus, in 804 inserts (T.O. Plastics, Minneapolis, $\mathrm{MN}$ ) containing $100 \%$ perlite (Carolina Perlite Co., Gold Hill, NC). Supplemental light was provided by light-emitting diode (LED) arrays (Fluence Spyder with PhysioSpec; Fluence Technologies, Austin, TX); photosynthetic photon flux density (PPFD) of $250 \mu \mathrm{mol} \cdot \mathrm{m}^{-2} \cdot \mathrm{s}^{-1}$ and 14-h daylength were maintained until ambient daylength reached $14 \mathrm{~h}$ (18 May in Athens, GA). Seedlings were transplanted to trade 1-gal containers (Classic 400; Nursery Supply, Agwam, MA) with $75 \%$ pine bark mulch, $20 \%$ compost, and $5 \%$ perlite medium mix (Foothills Compost, Grayson, GA) and grown in a glasshouse with temperatures of $24^{\circ} \mathrm{C}$ (day) and $20^{\circ} \mathrm{C}$ (night). Plants were topdressed with $21 \mathrm{~g}$ of 16N-3.5P-7.5K slow-release fertilizer (Pursell, Sylacauga, AL) and hand watered daily to container capacity with municipal water. When flowering occurred, controlled intraspecific pollinations of butterfly weed were performed in the same greenhouse environment to generate seed pods. Harvested pods were taken into the laboratory and seeds were separated from the pod to be surface-sterilized.

EXPERIMENTAL DESIGN OF STUDY ONE: EFFECTS OF MEDIUM TYPE ON ER suCCESS. The first study was performed to determine the optimal culture medium type for the germination and regeneration of autotrophic embryos harvested at $90 \mathrm{~d}$ after pollination (DAP). The medium type served as the treatment effect and included MS Basal Salt Mixture (SigmaAldrich, St. Louis, MO), MS Basal Salt Mixture at half strength (1/2 MS), and Woody Plant Medium [WPM (Sigma-Aldrich)]. Protocols for preparation were followed as published in the PhytoTechnology Laboratories (Lenexa, KS) technical information guide (2008), with $\mathrm{pH}$ adjusted to 5.7-5.9. After preparation, media were poured into either $100-\times 15-$ $\mathrm{mm}$ petri dishes (Thermo Fisher Scientific, Waltham, MA) or 14-fl oz sterilized polyethylene terephthalate (PET) cups (12FCB clear cup with DLKC16/24NH clear dome lid;
Southeastern Paper Group, Atlanta, GA). After being plated and cooled, plates were stored in a dark location held at $25 \pm 2{ }^{\circ} \mathrm{C}$ day/night temperatures until use. A single seed pod containing 117 seeds was harvested at 90 DAP. Seeds were randomly divided into three equal groups of 39 to be placed on the three medium types. Seeds designated for each medium treatment were then randomly subdivided into three replications, with 13 seeds in each replication. After randomly dividing seeds from each treatment into replications, seeds were taken to the laboratory, surface-sterilized, excised, and plated on petri dishes filled with MS, $1 / 2 \mathrm{MS}$, or WPM media.

EXPERIMENTAL DESIGN OF STUDY TWO: EFFECTS OF EMBRYO MATURITY ON ER success. The second study used a medium type from the first study ( $1 / 2 \mathrm{MS})$ to examine its ability to successfully germinate embryos at various DAP; embryo maturity was the treatment effect. In this study, two additional embryo maturity dates, 60 DAP and 30 DAP, were examined, and data from 90 DAP embryos in study one were used to discern differences among embryo maturity. A single seed pod containing between 72 and 117 seeds was harvested at each point of embryo maturity. The pod harvested at 90 DAP contained 117 seeds, of which 39 randomly selected seeds were subdivided into three replications with 13 seeds in each replication and used for statistical analysis in this study. The seed pod harvested at 60 DAP contained 72 seeds that were divided into four replications of 18 individually plated embryos. The pod harvested at 30 DAP contained 100 seeds. To maintain some homogeneity of replication numbers, only 72 randomly selected seeds were chosen from this seed pod and divided into four replications of 18 . After randomly dividing seeds from each treatment into replications, seeds were taken to the laboratory, surface-sterilized, excised, and plated on petri dishes filled with $1 / 2$ MS.

Preparation of the germination CONTROL. To compare ER germination rates in both studies to industry standard germination rates, a single pod was harvested at maturity (natural splitting of the pod). The mature seeds were immediately cold moist-stratified in damp sand (All-purpose Builder's Sand; 
Lowe's, Charlotte, $\mathrm{NC}$ ) at $2^{\circ} \mathrm{C}$ for 30 d. A randomized complete block of 39 seeds randomly selected from the pod (split into three replications of 13) were germinated in 804 inserts (T.O. Plastics) with 100\% perlite (Carolina Perlite Co.) inside a greenhouse at the College Station Greenhouse Complex at the University of Georgia Athens campus. Supplemental light was provided by LED arrays delivering a PPFD of $250 \mu \mathrm{mol} \cdot \mathrm{m}^{-2} \cdot \mathrm{s}^{-1}$ and a 14-h daylength that was maintained until ambient daylength reached $14 \mathrm{~h}$ (18 May in Athens, GA). Seed trays were misted with municipal water for $10 \mathrm{~s}$ every $10 \mathrm{~m}$ with temperatures at $24^{\circ} \mathrm{C}$ (day) and $20{ }^{\circ} \mathrm{C}$ (night). The germination percent was recorded $30 \mathrm{~d}$ after sowing.

SEed Surface sterilization. Surface sterilization occurred in a laboratory environment. Seeds were initially rinsed under tap water for $5 \mathrm{~min}$ before being placed in a sterile 500$\mathrm{mL}$ bottle filled with room temperature sterile water and $1 \mathrm{~mL}$ of detergent (Dawn; Procter \& Gamble, Cincinnati, $\mathrm{OH}$ ). The solution of soap and water was gently shaken for $4 \mathrm{~min}$ and then poured out; seeds were caught in a sterilized strainer. Seeds were rinsed with reverse osmosis water for 2 to $3 \mathrm{~min}$ to ensure the removal of residual soap. The next steps occurred under a laminar flow hood and all equipment was sterilized. Seeds were placed in a $100-\mathrm{mL}$ beaker filled with a $75 \%$ ethanol solution and agitated for $30 \mathrm{~s}$. Seeds were then transferred to another $100-\mathrm{mL}$ beaker filled with a $10 \%$ disinfectant (Roccal; Pfizer, New York, NY) solution and stirred for $1 \mathrm{~min}$. Seeds were transferred to a $500-\mathrm{mL}$ beaker filled with a $1.5 \%$ bleach solution (Clorox Co., Oakland, CA) and agitated for 3 min. Immediately after the bleach wash, seeds were transferred to another $500-\mathrm{mL}$ beaker filled with double deionized (DI) water. Seeds were agitated for $3 \mathrm{~min}$, and the DI washing process was repeated three times in different $500-\mathrm{mL}$ beakers. At that point the seeds were considered disinfected and could be stored in petri dishes sealed with laboratory film (parafilm; Sigma-Aldrich) until excision.

EMbryo RESCUE. After surface sterilization, embryos were excised under a laminar flow hood using a sterile scalpel on sterile filter paper; a dissecting microscope was used to improve the visibility of the embryos. Embryos of butterfly weed are small (length, $0.6 \mathrm{~cm}$ ); therefore, an initial lateral cut was made around the outside edge of seeds to avoid cutting into the embryo. After the initial cut, the thin testa (seedcoat) was peeled away from the embryo using forceps. Using either the scalpel or forceps, embryos were gently removed and placed on the predetermined medium type in 100- $\times 15-\mathrm{mm}$ petri dishes (Thermo Fisher Scientific). It should be noted that even though the dividing hilum scar appears to be an easier place to make the incision, a vertical excising cut down the middle of the seed will often puncture the embryo. Immediately after plating embryos on medium treatments in 100- $\times 15-\mathrm{mm}$ petri dishes (Thermo Fisher Scientific), dishes were placed in a dark room for $3 \mathrm{~d}$ at $22 \pm 2{ }^{\circ} \mathrm{C}$ day/night temperatures to break chemical dormancy. Embryos were transferred to a climate-controlled environment held at $22 \pm 2{ }^{\circ} \mathrm{C}$ day $/$ night temperatures and a 16-/8-h light/dark photoperiod with a PPFD of $50 \mu \mathrm{mol} \cdot \mathrm{m}^{-2} \cdot \mathrm{s}^{-1}$ provided by cool white fluorescent tubes. When an embryo had an actively growing radicle, embryos were re-plated in 14-fl oz sterilized PET cups (12FCB clear cup with DLKC16/24NH clear dome lid) and grown for $100 \mathrm{~d}$ in the first study and $70 \mathrm{~d}$ in the second study. It should be noted that embryos were initially germinated in petri dishes due to laboratory space limitations, but they could also be germinated directly in clear PET cups to minimize labor.

DATA COLLECTION AND STATISTICAL ANALYSIS. Data collection for both studies included average longest root length (centimeters), average shoot length (centimeters), germination percentage, and number of explants successfully generated (defined as reaching a height of 3 inches). To prevent contamination, embryos were not removed from their sterile containers to take measurements, with the exception of the final measurement date. Media on which embryos were placed was clear, and measurements were as accurate as possible. On petri dishes, root lengths were measured with a ruler from below; in sterile cups, root lengths were measured from the side to below, depending on root development. Shoot lengths were measured from the top of petri dishes or the side of sterile cups. Measurements were collected this way to reduce distortion of root and shoot lengths and obtain the most accurate data possible without exposing developing embryos to unnecessary contamination. The root length was measured from the root tip to where it joined either the callus or meristem tissue. Data collection began $10 \mathrm{~d}$ after plating embryos and continued at 10-d intervals for $50 \mathrm{~d}$ in both studies. Shoot length was measured from the base of the callus or meristem tissue to the uppermost meristematic tissue. Shoot length data collection in the first study began at $60 \mathrm{~d}$ and continued at 10-d intervals for $100 \mathrm{~d}$. Shoot length data collection in the second study began at $30 \mathrm{~d}$ and continued at 10- $\mathrm{d}$ intervals for $70 \mathrm{~d}$. Germination was defined as the number of seeds that successfully began radicle elongation and was reported as percentage data. The successful explant number was measured as plants alive in vitro at $100 \mathrm{~d}$ in the first study and at $70 \mathrm{~d}$ in the second study. A statistical analysis for both studies was performed using JMP (version 13.0; SAS Institute, Cary, NC). Data were analyzed to determine normality and homogeneity, with one-way analysis of variance (ANOVA) and separation of treatment means using Tukey's honestly significant difference test used in both studies to analyze root length, shoot length, and successful explant number variances. Germination percentage data were log-transformed before the one-way ANOVA to determine significance; then, they were back-transformed for reporting. Only data showing significant differences $(P \leq 0.05)$ among treatments are reported.

\section{Results and discussion}

STUdy ONE: EFFECTS OF MEDIUM TYPE ON ER SUCCESS. Average root length $( \pm S E)$ on $1 / 2$ MS medium $(3.50 \pm$ $0.51 \mathrm{~cm})$ was greater when compared with MS medium $(1.43 \pm 0.33 \mathrm{~cm})$ (Fig. 1). WPM was similar to MS and $1 / 2$ MS media, with an average root length of $1.98 \pm 0.36 \mathrm{~cm}$ (Fig. 1). Differences between root lengths became significant as early as $20 \mathrm{~d}$ after excision and maintained the separation through day 50 (Fig. 1). At 100 $\mathrm{d}$, MS and $1 / 2$ MS had similar shoot growth, and both had greater shoot 
lengths $(9.28 \pm 1.91 \mathrm{~cm}$ and $14.76 \pm$ $1.74 \mathrm{~cm}$, respectively) compared with WPM medium $(2.75 \pm 1.05 \mathrm{~cm})($ Fig.
2). When assessing combined root and shoot growth results, $1 / 2$ MS medium had both the greatest root growth

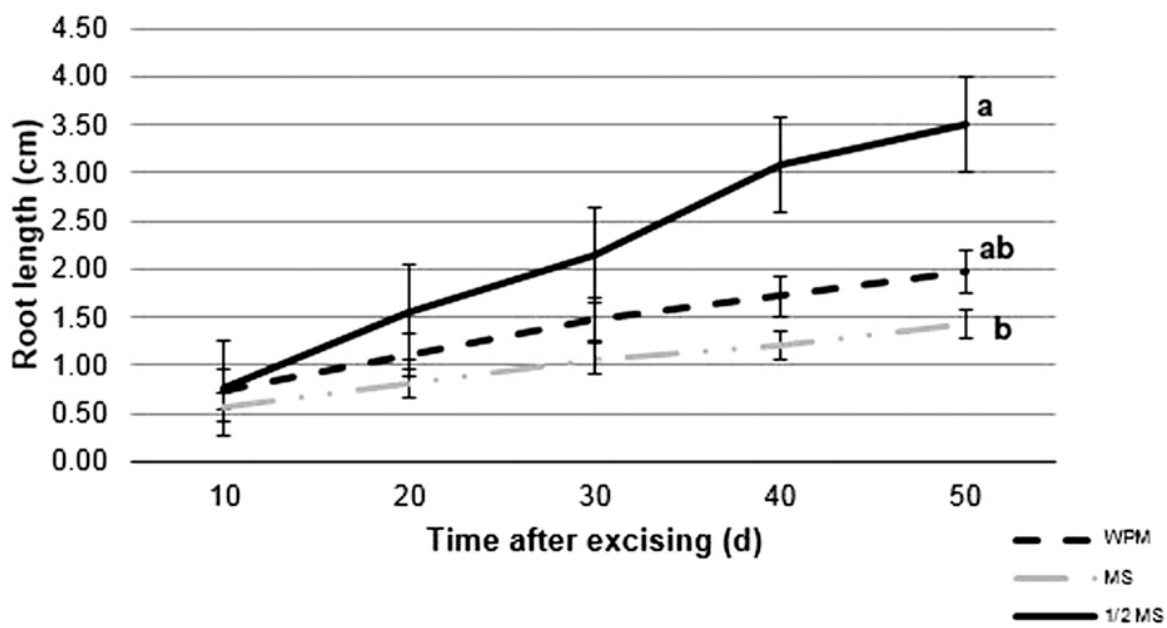

Fig. 1. Effect of half-strength Murashige and Skoog medium ( $1 / 2 \mathrm{MS})$, fullstrength Murashige and Skoog medium (MS), and woody plant medium (WPM) on root length over time when culturing butterfly weed embryos harvested 90 $\mathrm{d}$ after pollination (DAP). Bars represent means with SE at $P<0.05$. Letters indicate significance at day 50 based on Tukey's highly significant difference test at $P \leq 0.05 ; 1 \mathrm{~cm}=0.3937$ inch.

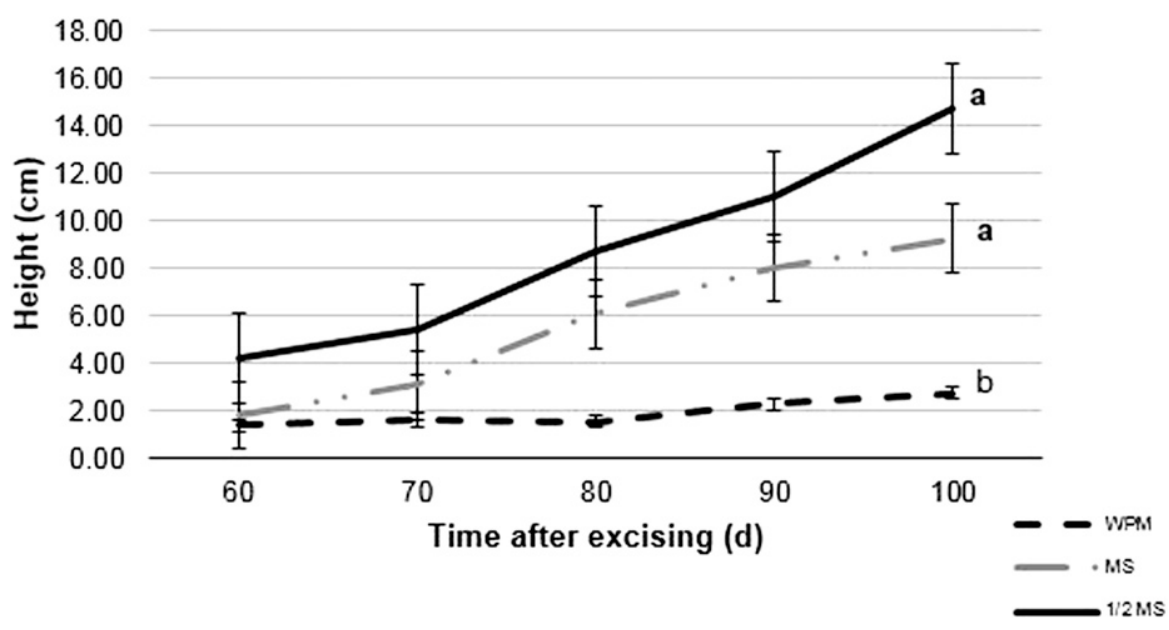

Fig. 2. Effect of half-strength Murashige and Skoog medium ( $1 / 2 \mathrm{MS})$, fullstrength Murashige and Skoog medium (MS), and woody plant medium (WPM) on shoot length over time when culturing butterfly weed embryos harvested 90 $\mathrm{d}$ after pollination (DAP). Bars represent means with SE at $\boldsymbol{P}<0.05$. Letters indicate significance at day 100 based on Tukey's highly significant difference test at $P \leq 0.05 ; 1 \mathrm{~cm}=0.3937$ inch.
$(3.50 \pm 0.51 \mathrm{~cm})$ and shoot growth $(14.76 \pm 1.74 \mathrm{~cm})$. Root lengths of indian ipecac reached $14.46 \mathrm{~cm}$ when plated on $1 / 2$ MS medium at a similar maturity (Sahai et al., 2010). Pendulous wax flower (Hoya wightii) achieved similar shoot growth (9.1 $\mathrm{cm}$ ) in MS medium at similar maturity (Lakshmi et al., 2010). Our results indicated that MS medium is ideal for the promotion of root and shoot growth, with $1 / 2$ MS being superior for butterfly weed.

Although comparisons of growth parameters among medium types are useful, to be a commercially viable ER technique, ER must be more effective when compared with the industry standard of germination in soilless substrate under greenhouse conditions. This study determined that by comparing germination percentages on MS, $1 / 2$ MS, and WPM to that of control (seeds germinated in perlite), $1 / 2$ MS $(97.43 \% \pm 2.00 \%)$ and MS $(94.88 \% \pm 4.29 \%)$ had higher germination rates compared with WPM $(82.05 \% \pm 3.1 \%)$ or perlite $(79.5 \% \pm$ $3.09 \%$ ) (Table 1). Commercially, high germination rates are important, but the survivability of plantlets is equally critical. When comparing the percentage of plants that survived $100 \mathrm{~d}$ (harvest date), $1 / 2$ MS was superior $(89.75 \%$ $\pm 5.50 \%)$ to MS $(51.00 \% \pm 9.74 \%)$ and WPM $(56.41 \% \pm 4.26 \%)$ (Table 1$)$. Similar results have been documented for mountain laurel [Kalmia latifolia (Li and Zhang, 2018)], rhododentrons [Rhododendron sp. (Eeckhaut et al., 2007)], roses [Rosa (Marchant et al., 1993)], and japanese holly [Ilex crenata (Yang et al., 2015)]; ER significantly increased germination rates compared with seed germination in soilless substrates. When assessing results such as germination rate, root growth, and shoot growth, $1 / 2$ MS was the superior medium for germination and growth of 90 DAP butterfly weed embryos.

Table 1. Effect of half-strength Murashige and Skoog medium ( $1 / 2 \mathrm{MS})$, full-strength Murashige and Skoog medium (MS), woody plant medium (WPM), and germination of fully mature butterfly weed seed on perlite under greenhouse conditions (control) on germination rates and survival rates of plantlets.

\begin{tabular}{llcccc}
\hline Medium & df & Germination (no.) & Germination (\%) & Final survival (no.) & Survival success (\%) \\
\hline WPM & 39 & 32 & $82.05 \mathrm{bc}^{\mathrm{z}}$ & $22 \mathrm{~b}$ & $56.41 \mathrm{~b}$ \\
MS & 39 & 37 & $94.88 \mathrm{ab}$ & $20 \mathrm{~b}$ & $51.00 \mathrm{~b}$ \\
$1 / 2$ MS & 39 & 38 & $97.43 \mathrm{a}$ & $35 \mathrm{a}$ & $89.74 \mathrm{a}$ \\
Perlite & 39 & 31 & $79.5 \mathrm{c}$ & - & - \\
\hline
\end{tabular}

${ }^{\mathrm{z}}$ Letters represent groupings based on Tukey's highly significant difference test at $P \leq 0.05$. 


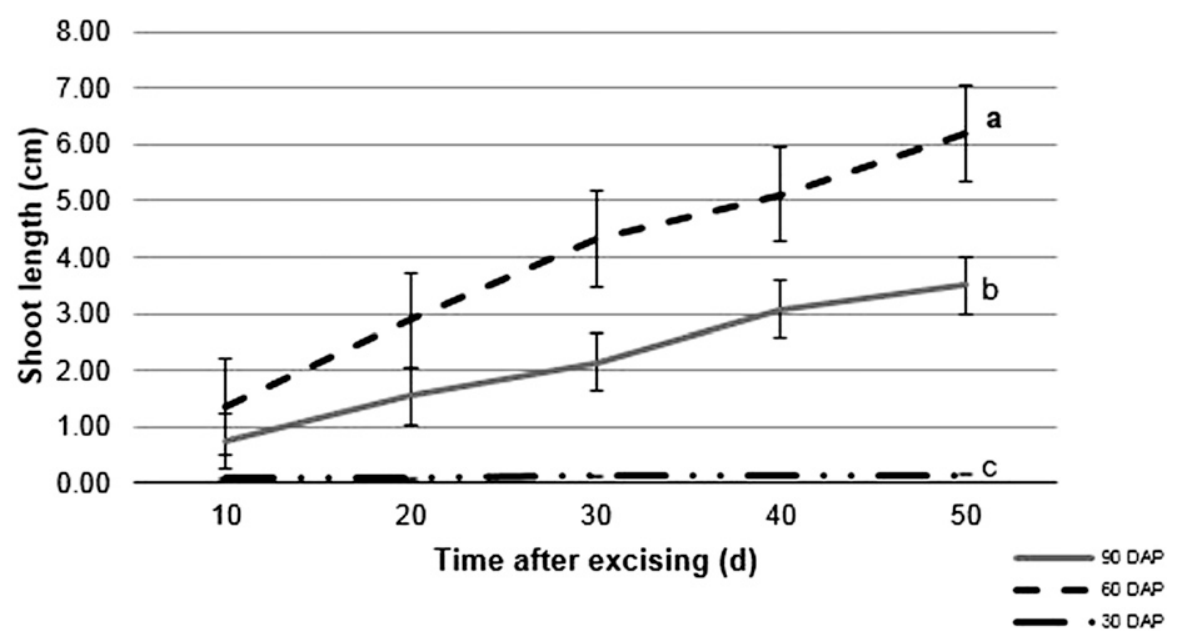

Fig. 3. Effect of butterfly weed embryo maturity on root length using halfstrength Murashige and Skoog medium. Embryo maturities of 90, 60, and 30 $\mathrm{d}$ after pollination (DAP) are displayed. Days after excising refers to the number days accrued after the successful removal of the embryo from the seedcoat. Bars represent means with SE at $P<0.05$. Letters indicate significance at day 50 based on Tukey's highly significant difference test at $P \leq 0.05 ; 1 \mathrm{~cm}=0.3937$ inch.

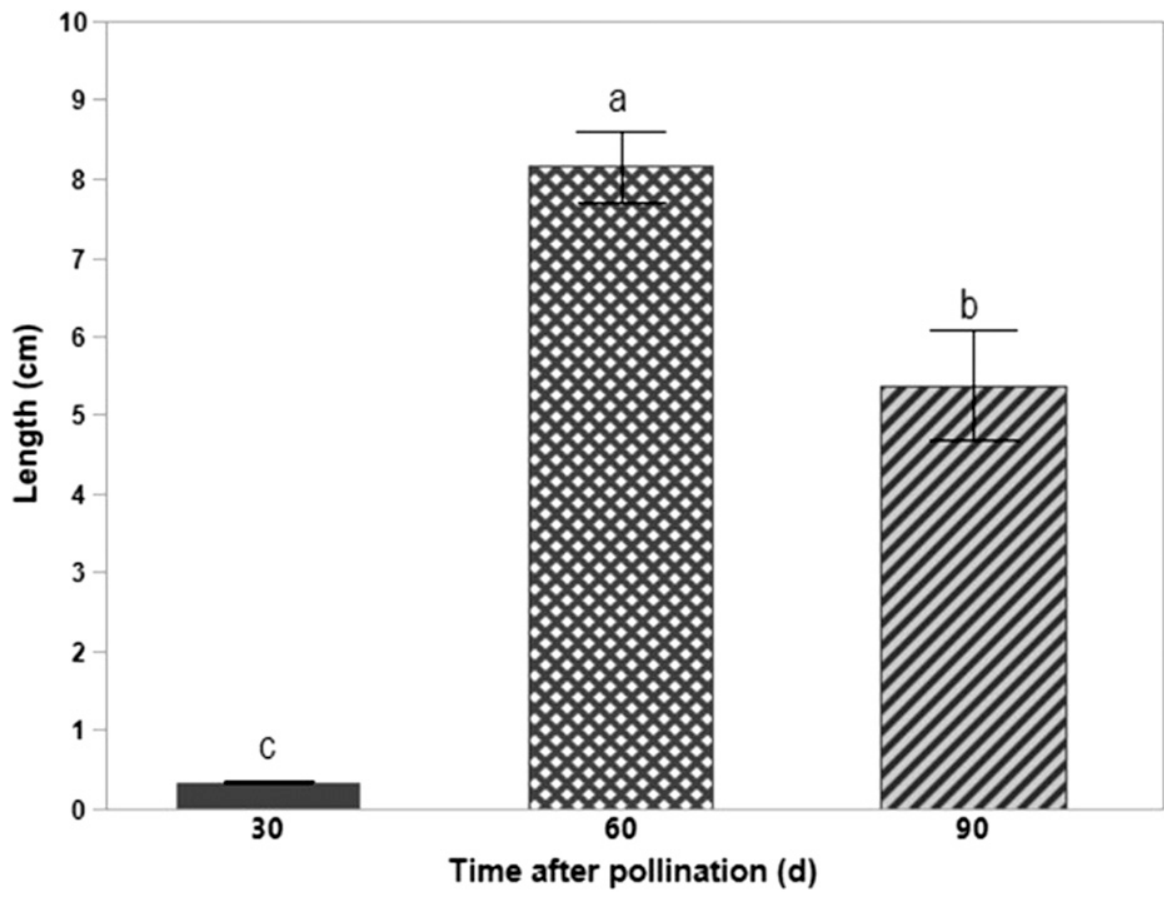

Fig. 4. Effect of butterfly weed embryo maturity on shoot length at $70 \mathrm{~d}$ after excising using half-strength Murashige and Skoog medium. Embryo maturities of 90,60 , and $30 \mathrm{~d}$ after pollination (DAP) are displayed. Days after excising refers to how many days accrued after the successful removal of the embryo from the seed. Bars represent means with $\mathrm{SE}$, and letters above bars represent groupings based on Tukey's highly significant difference test at $P \leq 0.05 ; 1 \mathrm{~cm}=0.3937$ inch.

STUdY TWO: EFFECTS OF EMBRYo MATURITY ON ER sUCCESS. The literature frequently describes ER as occurring a few days to a few weeks after pollination (George et al., 2008; Sharma et al., 1996). However, in study two, the objective was to determine the age when embryos were rates (Tsuchiya, 1954; Wyatt and Broyles, 1994). Orchid pods require 112-224 d to mature, but prematurely harvesting pods at 100-150 d after fertilization for ER drastically improved germination success rates (Knudson, 1922). The average amount of time a butterfly weed pod takes to reach maturity after pollination is $118.0 \pm 4.2 \mathrm{~d}$ (unpublished data). Therefore, after testing the efficacy of the ER protocol developed in study one, the determination was made to perform ER for seeds at 90 , 60 , and $30 \mathrm{DAP}$. The goal was to determine if 30-DAP and/or 60DAP embryos could be germinated and grown out without the aid of PGRs (in the autotrophic growth phase). One significant change made to the data collection in the second study was that the shoot measurements began at day 30 (rather than day 60) to better capture shoot growth curves that are more in accordance with commercial needs. Typically, tissue-cultured plant material is removed from sterile conditions and grown to a maximum of 3 to 5 inches (7.6-12.7 $\mathrm{cm})$ before being sold and/or transplanted (Mulhern, 2010). In study one, it was not anticipated that shoot growth would occur as quickly as it did. Root length measurements remained the same. Overlap in measurement dates from study one allowed embryo growth comparisons from embryos of different ages $(90,60$, and 30 DAP), allowing a more complete picture of growth and development.

Across the three embryo maturities, the root length of embryos rescued 60 DAP was longer $(6.20 \pm 0.36 \mathrm{~cm})$ than those of embryos harvested at 90 DAP $(3.50 \pm 0.51 \mathrm{~cm})$ or $30 \mathrm{DAP}(0.16 \pm$ $0.02 \mathrm{~cm}$ ) (Fig. 3). Embryos harvested at 90 DAP had longer root lengths $(3.50 \pm$ $0.51 \mathrm{~cm})$ than those harvested at 30 $\operatorname{DAP}(0.16 \pm 0.02 \mathrm{~cm})$ (Fig. 3$)$. Embryos harvested 60 DAP had greater shoot length $(8.16 \pm 0.44 \mathrm{~cm})$ than those harvested at 90 DAP $(5.38 \pm 0.69 \mathrm{~cm})$ or $30 \mathrm{DAP}(0.33 \pm 0.02 \mathrm{~cm})$ (Fig. 4$)$. Root length differences became significant as early as day 10 after excision and maintained the separation throughout the duration of the study (Fig. 3). As observed in study one, the germination rates for all ER DAP treatments on $1 / 2$ MS medium were greater $[100 \% \pm$ $0.00 \%$ (30 DAP); $100 \% \pm 0.00 \%(60$ $\mathrm{DAP})$; and $97.43 \% \pm 4.47 \%(90 \mathrm{DAP})]$ than the germination rates of mature 
Table 2. Effect of butterfly weed embryo maturity [90, 60, and $30 \mathrm{~d}$ after pollination (DAP)] on germination and survival rates are reported in addition to germination rates of seed sown in perlite under greenhouse conditions (control).

\begin{tabular}{lccccc}
\hline DAP & No. & Germination (no.) & Germination (\%) & Final survival (no.) & Survival success (\%) \\
\hline 90 & 39 & 38 & $97.43 \mathrm{a}^{\mathrm{z}}$ & $35 \mathrm{a}$ & $89.74 \mathrm{a}$ \\
60 & 72 & 72 & $100 \mathrm{a}$ & $69 \mathrm{a}$ & $95.83 \mathrm{a}$ \\
30 & 72 & 72 & $100 \mathrm{a}$ & $72 \mathrm{a}$ & $100 \mathrm{a}$ \\
Perlite & 39 & 31 & $72.38 \mathrm{~b}$ & - & - \\
\hline
\end{tabular}

${ }^{\mathrm{z}}$ Letters represent groupings based on Tukey's highly significant difference test at $P \leq 0.05$

seeds on perlite $[72.38 \% \pm 6.91 \%$ (control)] (Table 2). Survival rates were similar across all treatments $[100 \% \pm$ $0.00 \%$ (30 DAP); $95.83 \% \pm 1.73 \%(60$ $\mathrm{DAP})$; and $89.74 \% \pm 5.50 \%(90 \mathrm{DAP})]$, but survivability does not equate to successful embryo development (Table 2, Fig. 4). For example, the $30 \mathrm{DAP}$ treatment had the highest survival rate $(100 \%)$ but the smallest root $(0.16 \pm$ $0.02 \mathrm{~cm})$ and shoot length $(0.33 \pm 0.02$ $\mathrm{cm}$ ) (Figs. 3 and 4, Table 2), making it the least successful treatment. Overall, embryos harvested 60 DAP yielded the greatest $\operatorname{root}(6.20 \pm 0.36 \mathrm{~cm})$ and shoot growth $(8.16 \pm 0.44 \mathrm{~cm})$ compared with other treatments, with comparable germination and embryo survival rates (Figs. 3 and 4 , Table 2).

These results indicated that butterfly weed embryos reach an autotrophic stage by $60 \mathrm{DAP}$, which is $58 \mathrm{~d}$ earlier than when pods are typically harvested $(118.0 \pm 4.2 \mathrm{~d})$. From a commercial standpoint, this could significantly reduce the time needed to produce a salable liner. Using traditional seed-based propagation, a commercial grower would harvest seeds 118 DAP, stratify for $30 \mathrm{~d}$, germinate under greenhouse conditions (requiring $30 \mathrm{~d}$ ), and grow out for $30 \mathrm{~d}$ to reach a salable size, with a total of $208 \mathrm{~d}$ ( 29.7 weeks) invested in propagation. Conversely, seeds required for ER could be harvested 60 DAP and require an additional $60 \mathrm{~d}$ in culture to reach a salable size of 3 inches (Fig. 4), for a total of 120 $\mathrm{d}$ (17.1 weeks) invested in propagation. In this scenario, ER results in a reduction in butterfly weed propagation time of $88 \mathrm{~d}$.

\section{Conclusions}

This study documented a successful protocol for ER in butterfly weed, including surface sterilization techniques, excision methods, stratification times, medium type/strength, and embryo harvesting time. Previous studies investigated either embryogenesis of species in the milkweed family (but not milkweed species) or organogenesis of milkweed from leaf or meristem tissue. To our knowledge, this is the first study to investigate ER of embryonic tissue from seeds, and it is the first to document the effect of embryo maturity on the successful development of explants in culture. Because methods for ER vary from species to species, this study aimed at providing a commercial ER protocol for butterfly weed, with the hope that this protocol may be applicable to other milkweed species. Results indicated that $1 / 2$ MS medium yielded ER seedlings with greater root and shoot lengths with comparable survival rates compared with MS and WPM. This was likely due to the natural affinity of milkweed species for soils with low nutritional content, which most closely aligned with $1 / 2$ MS medium (Stevens, 1945). These results indicated that ER could be a commercially viable alternative to germination of milkweed species in soilless substrates, reducing propagation time by $88 \mathrm{~d}$ ( 12.6 weeks ) and, as a result, possibly increasing profitability. Another goal of this study was to determine at what point embryo maturity affected embryo germination and growth. Embryos rescued at 30 DAP resulted in the lowest root and shoot growth, whereas 60 DAP yielded the highest root and shoot growth. Although there was no difference in germination percentages among embryos of differing maturities or among differing medium types, ER germination rates were uniformly higher than germination rates of fully mature seed sowed in soilless substrate. These findings provide a starting point for improved commercial propagation of butterfly weed, as well as for potentially offering a viable propagation protocol for threatened and/or endangered milkweed species to enhance restoration efforts.

\section{Literature cited}

Bhojwani, S.S. and M.K. Razdan. 1986. Introductory history, p. 1-17. In: S.S. Bhojwani and M.K. Razdan (eds.). Plant tissue culture: Theory and practice. Vol. 5. Elsevier, Amsterdam, The Netherlands.

Bridgen, M.P. 1994. A review of plant embryo culture. HortScience 29:1243-1246.

Broyles, S.B. 2002. Hybrid bridges to gene flow: A case study in milkweeds (Asclepias). Evolution 56:1943-1953.

Conger, B.V. 1981. Cloning agricultural plants via in-vitro techniques. CRC Press, Boca Raton, FL.

Dunwell, J.M. 1986. Pollen, ovule and embryo culture as tools in plant breeding, p. 375-404. In: L.A. Withers and P.G. Alderson (eds.). Plant tissue culture and its agricultural applications. Butterworths, London, UK.

Eeckhaut, T., E. De Keyser, J. Van Huylenbroeck, J. De Riek, and E. Van Bockstaele. 2007. Application of embryo rescue after interspecific crosses in the genus Rhododendron. Plant Cell Tissue Organ Cult. 89:29.

George, E.F., M.A. Hall, and G.J. DeKlerc. 2008. Plant tissue culture procedureBackground, p. 1-28. In: E.F. George, M.A. Hall, and G.-J. De Klerk (eds.). Plant propagation by tissue culture. 3rd ed. Springer, Dordrecht, The Netherlands.

Groet, S.S. and G.H. Kidd. 1981. Somatic embryogenesis and regeneration from milkweed cell cultures. Biomass 1:93-97.

Hannig, E.E. 1904. Zur Physiologie pflanzlicher Embryonen. I. Über die Kultur von Cruciferen-embryonen ausserhalb des Embryosacks. Botanische Zeitung 62:45-80.

Kephart, S.R. 1981. Breeding systems in Asclepias incarnata L., A. syriaca L., and $A$. verticillata L. Amer. J. Bot. 68:226-232.

Kim, S.W., D.S. In, P.S. Choi, and J.R. Liu. 2004. Plant regeneration from immature zygotic embryo-derived embryogenic calluses and cell suspension cultures of Catharanthus roseus. Plant Cell Tissue Organ Cult. 76:131-135.

Knudson, L. 1922. Non-symbiotic germination of orchid seeds. Bot. Gaz. 73:1-25. 
Lakshmi, S.R., J.F. Benjamin, T.S. Kumar, G.V.S. Murthy, and M.V. Rao. 2010. In vitro propagation of Hoya wightii ssp. palniensis KT Mathew, a highly vulnerable and endemic species of Western Ghats of Tamil Nadu, India. Afr. J. Biotechnol. 9: 620-627.

Li, H. and D. Zhang. 2018. In vitro seed germination of Kalmia latifolia L. hybrids: A means for improving germination and speeding up breeding cycle. HortScience 53:535-540.

Lipow, S.R. and R. Wyatt. 2000. Single gene control of postzygotic self-incompatibility in poke milkweed, Asclepias exaltata L. Genetics 154:893-907.

Marchant, R., J.B. Power, M.R. Davey, and J. Chartier-Hollis. 1993. Embryo rescue, for the production of $F_{1}$ hybrids, in english rose. Euphytica 74:187-193.

Morel, G. 1960. Producing virus-free cymbidium. Amer. Orchid Soc. Bull. 29:495497.

Mulhern, B. 2010. Preserving the future. GrowerTalks 74(7):38-39.

Pramanik, T.K. and S.K. Datta. 1986. Plant regeneration and ploidy variation in culture derived plants of Asclepias curassavica L. Plant Cell Rpts. 5:219-222.
Sahai, A., A. Shahzad, and S. Sharma. 2010. Histology of organogenesis and somatic embryogenesis in excised root cultures of an endangered species Tylophora indica (Asclepiadaceae). Austral. J. Bot. 58:198-205.

Seavey, S. and K. Bawa. 1986. Late-acting self-incompatibility in angiosperms. Bot. Rev. 52:202-205.

Shannon, T.R. and R. Wyatt. 1986. Pollen germinability of Asclepias exaltata: Effects of flower age, drying time, and pollen source. Syst. Bot. 11:322-325.

Sharma, D.R., R. Kaur, and K. Kumar. 1996. Embryo rescue in plants - A review. Euphytica 89:325-337.

Sparrow, F.K. and N.L. Pearson. 1948. Pollen compatibility in Asclepias syriaca. J. Agr. Res. 77:187-199.

Stephenson, K.K. and J.W. Fahey. 2004. Development of tissue culture methods for the rescue and propagation of endangered Moringa sp. germplasm. Econ. Bot. 58:S116-S124.
Stevens, O.A. 1945. Cultivation of milkweeds. North Dakota Agr. Expt. Sta. Bul. 333.

Tsuchiya, I. 1954. Germination of orchid seeds from premature pods. Na Pua Okika o Hawaii Met 4:11-16.

Whiting, A.G., 1943. A summary of the literature on milkweeds (Asclepiassp.) and their utilization. U.S. Dept. Agr. Bibliographical Bul. No. 2.

Woodson, R.E. 1954. The North American species of Asclepias L. Ann. Mo. Bot. Gard. 41:1-211.

Wyatt, R. and S.B. Broyles. 1994. Ecology and evolution of reproduction in milkweeds. Annu. Rev. Ecol. Syst. 25:423441 .

Yang, Y., D. Zhang, Z. Li, X. Jin, and J. Dong. 2015. Immature embryo germination and Its micropropagation of Ilex crenata Thunb. HortScience 50:733737. 